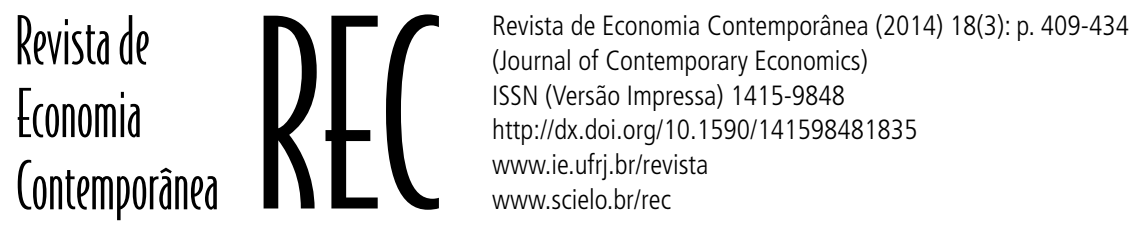

\title{
ABERTURA COMERCIAL E DESIGUALDADE DE RENDIMENTOS: ANÁLISE PARA AS REGIÕES BRASILEIRAS
}

\author{
Álvaro Barrantes Hidalgo ${ }^{a}$ \\ Maria de Fátima Sales ${ }^{b}$
}

\begin{abstract}
aPrograma de Pós-Graduação em Economia (PIMES) da Universidade Federal de Pernambuco (UFPE). bPrograma de Pós-Graduação em Economia Regional (PPE) da Universidade Estadual de Londrina (UEL).
\end{abstract}

Artigo recebido em 01/11/2013 e aprovado em 26/01/2015.

RESUMO: Este trabalho estuda os efeitos da abertura comercial e da globalização sobre a distribuição da renda nas regiões brasileiras levando em conta a dimensão espacial. O modelo empírico apoia-se no modelo desenvolvido por Venables e Limão (2002), que formalizaram a relação entre especialização regional e localização geográfica, mostrando que a produção e os padrões de comércio dependem não apenas da dotação de fatores de cada região, mas, também, da localização geográfica e dos custos de transporte. Foram estimados modelos de dados em painel para os principais mercados de destino das exportações brasileiras. Os resultados sinalizam que para as regiões mais desenvolvidas do Brasil o comportamento dos salários relativos parece seguir as previsões da teoria de Stolper-Samuelson, ao passo que nas regiões em desenvolvimento (Norte e Nordeste), os salários relativos para o trabalho não qualificado apresentam-se menores, resultado este contrário ao efeito Stolper-Samuelson, porém, previsto pelo modelo teórico apresentado.

PALAVRAS-CHAVE: Liberalização comercial; desigualdades salariais; Brasil.

\section{CLASSIFICAÇÃO JEL: F16.}

Correspondência para Álvaro Barrantes Hidalgo.

E-mail: abarrantes@uol.com.br. 


\section{TRADE OPENNESS AND INCOME INEQUALITY: ANALYSIS FOR BRAZILIAN REGIONS}

ABSTRACT: This work studies the effects of trade liberalization and globalization over income distribution in the Brazilian regions taking into account the spatial dimension. The empirical model is based on the model developed by Venables and Limão (2002), who formalized the relationship between regional specialization and geographical location, and showed that production and trade patterns depend not only on the endowments of each region, but also the geographical location and transport costs. Panel data models for target markets were estimated using Brazilian export data. The results indicate that in the more developed regions of Brazil the behavior of relative wages seems to follow the predictions of the Stolper-Samuelson theory, while in the developing regions (North and Northeast), relative wages for unskilled labor are smaller, a result that despite being contrary to the Stolper-Samuelson effect has been predicted by the theoretical model presented.

KEYWORDS: Trade liberalization; wage inequalities; Brazil.

\section{INTRODUÇÃO}

Nas últimas décadas as exportações brasileiras apresentaram um crescimento significativo e uma mudança na sua estrutura, que estão relacionados com o processo de crescimento econômico, a expansão do comércio mundial e as estratégias comerciais que foram adotadas pela economia brasileira no passado. A partir do fim da década de 1980, os formuladores da política econômica brasileira começaram a introduzir algumas medidas de livre comércio, a fim de tornar a economia brasileira mais competitiva e moderna. Esperava-se que essas medidas de abertura comercial levassem a uma melhoria na eficiência da economia nacional, promovendo uma melhor alocação intersetorial dos recursos, criando as bases para uma inserção mais competitiva na economia internacional. Desse modo, a abertura da economia pretendia promover uma mudança em relação ao passado e integrar a economia brasileira na globalização, em que as atividades menos competitivas deveriam ser substituídas por outras de maior produtividade.

Paralelamente, nessa época, o fenômeno da globalização e a formação dos blocos comerciais foram intensificados. Esse processo procurava eliminar as barreiras intrarregionais à livre mobilidade de bens, serviços e capitais, criando um mercado ampliado e que permitisse uma maior complementaridade das economias nacionais, $o$ aumento do comércio e o incremento da capacidade competitiva baseada nas vantagens naturais de cada país.

O processo de abertura comercial teve significativos efeitos sobre a economia brasileira, sendo importante conhecer quais têm sido esses efeitos que aconteceram não apenas sobre a produtividade, mas também sobre o grau de concorrência das empresas; sobre o emprego, salários, distribuição da renda; sobre o comércio e as contas do setor externo; e, em geral, sobre todo o processo de crescimento econômico. Algumas dessas questões já foram objetos de estudos e debates na literatura econômica. Em trabalhos realizados para a economia brasileira, Hidalgo (2002) e Hidalgo e Da Mata (2009) analisam, por exemplo, os efeitos da abertura sobre a produtividade no Brasil não apenas em nível agregado, mas também em nível de firmas exportadoras versus firmas não exportadoras. Paralelamente, nos trabalhos de Campos, Hidalgo e Da Mata (2007) e (2008), discutem-se alguns dos efeitos da abertura sobre a distribuição da renda. O debate no Brasil sobre a relação entre abertura, comércio e distribuição da renda tem sido intenso e nem sempre com resultados conciliatórios ${ }^{1}$. No último traba-

Alguns desses trabalhos serão relacionados a seguir. Barros et al. (2001) e Pedroso e Ferreira (2000) encontraram efeitos insignificantes da abertura sobre a distribuição da renda no Brasil. O primeiro chegou a essa conclusão com base em modelo de equilíbrio geral, enquanto o segundo utilizou modelos econométricos de corte transversal e de painel. Por outro lado, Ferreira e Machado (2001), utilizando o modelo Heckscher-Ohlin-Samuelson, encontraram resultados que dão suporte ao modelo, ou seja, os 
lho citado, os autores chegaram à conclusão de que independentemente do tamanho da firma e do nível de qualificação do trabalhador, firmas exportadoras remuneram melhor seus trabalhadores do que as não exportadoras. Também se mostra nesse trabalho que o prêmio pela qualificação entre exportadoras versus não exportadoras é maior nas firmas com até 99 empregados e uma correlação positiva entre comércio intra-indústria e desigualdades salariais.

Entretanto, os estudos que foram realizados para o Brasil sobre a relação entre abertura e distribuição da renda foram feitos com dados nacionais, e não foram levadas em conta as particularidades de cada região brasileira nem os impactos da abertura sobre a distribuição da renda em nível regional.

Dessa forma, o objetivo deste trabalho consiste em estudar os efeitos da liberalização comercial e da globalização sobre a distribuição da renda levando em conta a dimensão espacial, que geralmente é negligenciada nos modelos tradicionais. Pretende-se analisar os efeitos da liberalização comercial sobre os níveis salariais e o prêmio pela qualificação em nível regional. Vários motivos justificam a análise dessa questão. Em primeiro lugar, se os fatores de produção não forem perfeitamente móveis, a resposta de seus preços ao processo de liberalização comercial pode ser regionalmente heterogênea, não sendo possível identificar o efeito Stolper-Samuelson quando a análise for feita de forma agregada para toda a economia. Ademais, o estudo dessa questão é relevante levando em conta a existência de disparidades regionais na economia brasileira, a existência de regiões diferentemente dotadas de recursos produtivos e também o fato das regiões brasileiras estarem diferentemente integradas à economia internacional ${ }^{2}$.

setores intensivos em trabalho aumentaram sua participação no emprego total e quanto mais intensivo em trabalho é o setor, maior é a redução no preço observada após a abertura. Machado e Moreira (2001) encontraram para o período 1985-1997 que o comércio internacional impactou negativamente sobre a demanda de trabalho menos qualificado. Porém, para o subperíodo 1990-1993, encontraram que houve uma preferência pelo trabalho menos qualificado, enquanto para o subperíodo 1993-1997 parece ter ocorrido uma mudança tecnológica com viés para o trabalho qualificado. Sacconato e Menezes-Filho (2005) examinaram os diferenciais de salários entre trabalhadores nos Estados Unidos e no Brasil, encontrando evidências de que os retornos à educação no Brasil vêm caindo ao longo dos anos, com tendência de equalização internacional. Também os setores que mais empregam mão de obra qualificada são os mesmos nos dois países, porém, as desigualdades são mais acentuadas no Brasil. Arbache e Corseuil (2004) concluíram que o efeito da abertura sobre o emprego e salários foi negligenciável. Porém, Arbache (2003) constatou que os trabalhadores das firmas exportadoras no Brasil são mais qualificados que os trabalhadores das firmas não exportadoras e que economias de escala e qualificação são elementos importantes para explicar a inserção internacional das firmas brasileiras, em consonância com os resultados portantes para explicar a inseçao internacional das firmas brasileiras, em consonância com os resultados de De Negri (2003). Finalmente, De Negri et al. (2005) mostraram que firmas inovadoras pagam salários mível de escol mais inta dessas empresas inovadoras, e que as mesmas apresentam economias de escala na produccão.

2 No Brasil, dadas as dimensões territoriais e a heterogeneidade produtiva das diversas regiões, é de se esperar que os efeitos do comércio externo não se propaguem de maneira homogênea. Vale ressaltar, nesse
$\mathrm{Na}$ economia brasileira as regiões mais desenvolvidas, Sul e Sudeste, estão mais integradas à economia internacional do que as regiões menos desenvolvidas, como é o caso do Nordeste. Os efeitos da liberalização comercial sobre as regiões brasileiras têm sido pouco estudados.

Espera-se, com este trabalho, contribuir para a literatura econômica, com análises sobre a relação entre comércio e distribuição da renda nas regiões brasileiras, e agregar informações aos trabalhos realizados até o momento na tomada de decisões sobre a definição de políticas de comércio exterior levando em conta a dimensão regional.

A fim de atingir os objetivos, na seção 2 serão apresentados os aspectos teóricos do modelo utilizado na análise e a metodologia a ser utilizada nas estimações. Na seção 3 serão apresentados os principais resultados empíricos obtidos, e na seção 4 serão apresentadas as conclusões do trabalho.

\section{ASPECTOS TEÓRICOS E METODOLÓGICOS}

\section{ASPECTOS TEÓRICOS}

O estudo dos efeitos da liberalização comercial sobre a distribuição da renda em nível regional está apoiado em modelo desenvolvido por Venables e Limão (2002) ${ }^{3}$. Estes autores formalizaram a relação entre especialização regional e a localização geográfica, mostrando que a produção e os padrões de comércio dependem não apenas da dotação de fatores de cada região, mas, também, da localização geográfica e dos custos de transporte dos diferentes bens produzidos. Dessa forma, os autores mostram que os resultados tradicionais da teoria das proporções dos fatores, por exemplo, o teorema Stolper-Samuelson, se mantém apenas em determinadas localizações geográficas.

\subsubsection{O MODELO}

A seguir vamos explicitar o modelo proposto e discutir primeiramente a relação entre preços dos bens e preços dos fatores de produção. O modelo está inspirado na teoria

contexto, que as exportações e importaç̃es brasileiras ao longo do tempo não tiveram desempenho unicom o Mercosul.

3 O modelo de Venables e Limão tem sido submetido a evidências empíricas em nível internacional. Ver, por exemplo, o artigo de Chiquiar (2008). 
das proporções de fatores e a análise será feita seguindo abordagem gráfica introduzida na literatura por Abba Lerner (1932). A análise apresentada segue também Chiquiar (2008), porém, com algumas adaptações para a realidade brasileira.

O modelo pode ser descrito da seguinte forma. Considere uma economia pequena no comércio internacional dividida em duas regiões: uma região mais desenvolvida (A) e uma região menos desenvolvida (B) ${ }^{4}$. Admita que nessa economia sejam produzidos três tipos de bens: um bem industrializado (I) intensivo em trabalho qualificado, um bem intensivo em trabalho não qualificado $(\mathrm{M})$ e um bem não comercializável (N), agricultura para consumo interno, por exemplo. Admita, também, a existência de apenas dois fatores de produção: trabalho qualificado $(\mathrm{H})$ e trabalho não qualificado (L). Vamos chamar os preços desses dois fatores, respectivamente, WH e WL. Suponha, ainda, que as intensidades fatoriais dos bens estejam ordenadas da seguinte forma: o bem I é o mais intensivo em trabalho qualificado, seguido pelo bem M, enquanto o bem $\mathrm{N}$ é o menos intensivo em trabalho qualificado. Os três bens participam de livre comércio dentro do país, mas em nível internacional apenas os bens I e M participam de comércio.

O modelo postula imperfeita mobilidade de fatores dentro do país. Desta forma, as dotações de fatores são regionalmente diferentes dentro do país, e admite-se que a região A seja relativamente mais bem dotada de trabalho qualificado quando comparada com a região B, e que ela produz os bens I e M. Por outro lado, a região B, abundante em trabalho não qualificado, produz os bens $\mathrm{M}$ e $\mathrm{N}$.

\subsubsection{EQUILÍBRIO DE ECONOMIA FECHADA}

A relação entre preços de bens e preços de fatores, em equilíbrio de economia fechada, pode ser representada na Figura 1, seguindo a análise de Abba Lerner (1932).

As linhas de preços relativos dos fatores mostram que no equilíbrio o salário relativo do trabalho não qualificado é maior na região $\mathrm{A}$ do que na região $\mathrm{B}$, em outras palavras, o prêmio pela qualificação é maior na região $\mathrm{B}$ do que na região $\mathrm{A}$.

${ }^{4} \mathrm{O}$ modelo pode ser ampliado para considerar mais de duas regiões.
Figura 1 - Equilíbrio de economia fechada

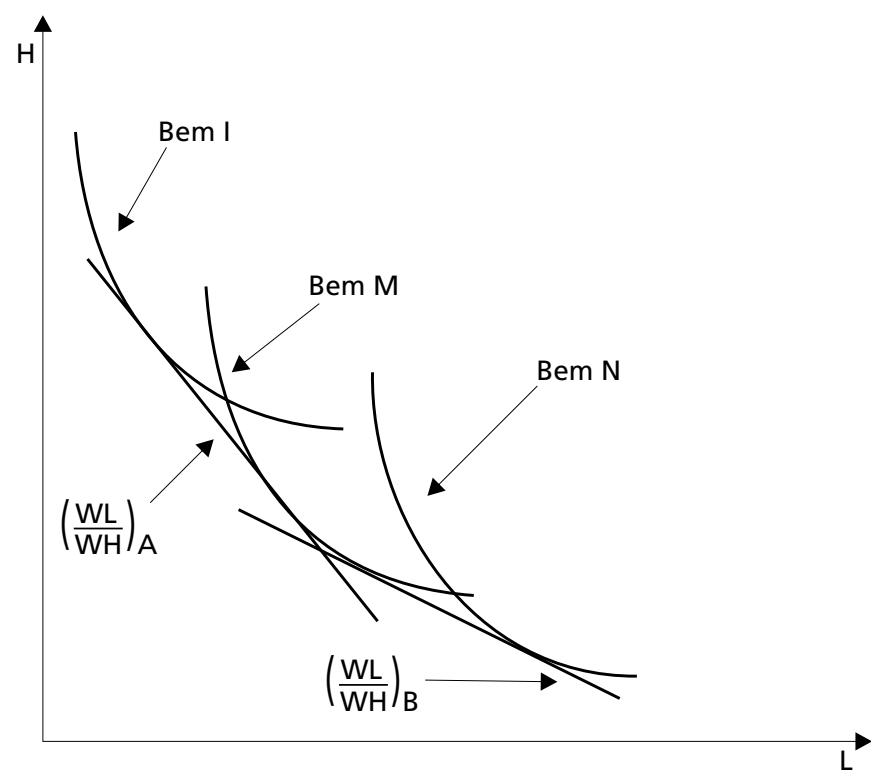

Fonte: Chiquiar (2008)

\subsubsection{EQUILÍBRIO DE ECONOMIA ABERTA}

Admita agora que a economia estabelece o livre comércio com o resto do mundo. Admita também que o resto do mundo seja relativamente mais bem dotado de trabalho qualificado do que o país doméstico. Analisando os preços dos bens comercializáveis e considerando o bem I como sendo o numerário, temos que após o comércio o preço relativo do bem $\mathrm{M}$ aumenta, levando a um deslocamento da isoquanta de valor unitário do bem M para dentro, como mostrado na Figura 2, a seguir.

Temos agora que desenhar duas linhas de isocustos tangentes a ambas as isoquantas (cada região produz apenas dois bens conforme já foi dito); a declividade dessas linhas está dada pelo negativo da razão WL/WH. É visivelmente claro, pela inclinação aumentada da linha de isocusto $(\mathrm{WL} / \mathrm{WH})_{\AA}$, que a nova relação $\mathrm{WL} / \mathrm{WH}$ é maior que a anterior, ou seja, um preço relativo de $\mathrm{M}$ mais alto implica uma razão WL/WH mais elevada em A. Por outro lado a inclinação da linha de isocusto (WL/WH) ${ }_{\mathrm{B}}$ agora é menor. Em outras palavras, o preço relativo dos insumos (WL/WH) responde diferentemente em cada região; o salário do trabalho não qualificado aumenta em $\mathrm{A}$, enquanto o prêmio pela qualificação aumenta em $B$. 
Figura 2 - Equilíbrio de economia aberta

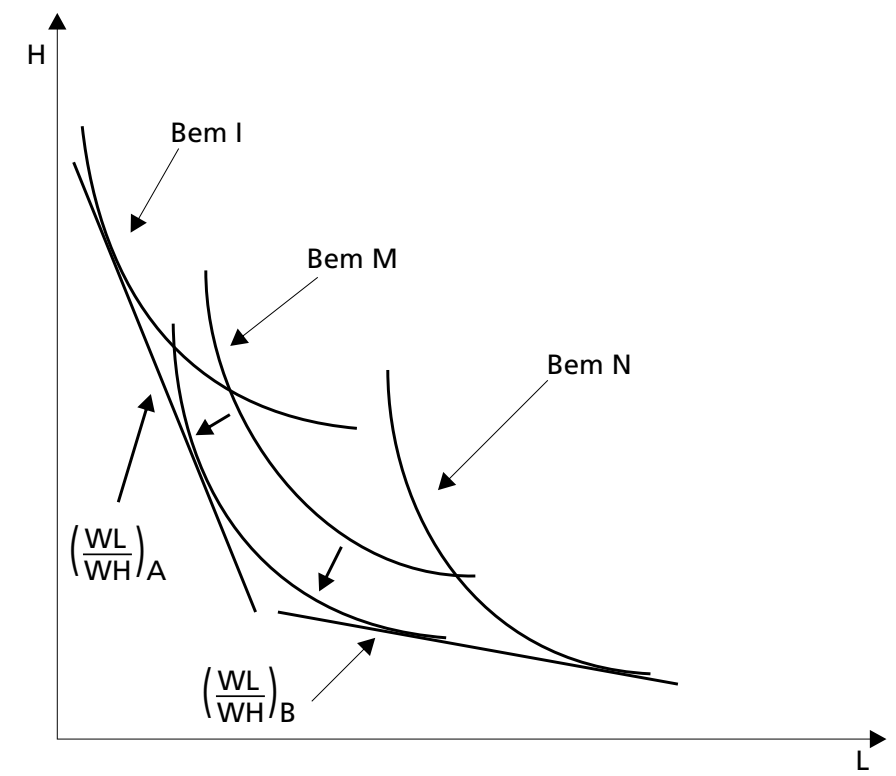

Fonte: Chiquiar (2008).

Assim, a análise do modelo apresentado parece mostrar que a liberalização comercial leva a movimentos opostos nos preços relativos dos fatores em cada uma das regiões consideradas. Esse movimento diferente dos preços dos fatores nas duas regiões decorre do fato de que do ponto de vista da região A, mais desenvolvida e mais integrada à economia internacional, o preço que aumentou foi o do bem intensivo em trabalho não qualificado, ao passo que do ponto de vista da região B, menos desenvolvida e menos integrada à economia internacional, o preço que aumentou foi o do bem intensivo em trabalho qualificado nessa região. Dentro de cada região esses resultados parecem coerentes com o teorema Stolper-Samuelson. No modelo explicitado a região mais desenvolvida está mais integrada ao comércio internacional, ela só produz bens comercializáveis, ao passo que a região menos desenvolvida produz um bem internacional e um bem não comercializável.

Levando em conta que a economia que estamos considerando é relativamente mais bem dotada de trabalho não qualificado em relação ao estrangeiro, o comportamento dos preços dos fatores da região mais integrada à economia internacional parece mais coerente com a teoria das proporções de fatores. Por outro lado, a região menos integrada ao comércio internacional mostra comportamento dos preços de fa- tores oposto ao previsto pela teoria de Stolper-Samuelson. Dessa forma, o comércio pode aumentar a desigualdade na distribuição de renda em algumas regiões ${ }^{5}$.

\subsubsection{O PROBLEMA DOS CUSTOS DE TRANSPORTE}

A importância dos custos de transporte no comércio internacional tem sido objeto de estudo por parte de diversos economistas. Samuelson (1954) sugeriu uma forma simples de tratar o problema. O autor postula que assim como apenas uma fração de gelo exportado chega ao destino como gelo sólido, para transportar uma unidade de um bem através do oceano é preciso pagar alguma fração do mesmo. Samuelson mostra que caso os custos de transporte sejam muito elevados, o bem pode tornar-se não comercializável. Mais recentemente, Venables e Limão (2002) realizaram uma análise mais aprofundada, analisando a relação entre padrões regionais de especialização e a localização geográfica. Os autores mostraram que a produção, os preços dos fatores de produção e as rendas variam entre as regiões em função da distância destas em relação aos principais mercados internacionais, e que os principais resultados da teoria de Heckscher-Ohlin mantêm-se apenas em determinadas localidades. Caso os custos de transporte sejam muito elevados, então os preços dos bens e dos fatores de produção podem estar determinados apenas por condições locais e não por condições no mercado internacional, como previsto pela teoria de comércio.

A seguir apresentaremos um resumo do modelo proposto por Venables e Limão (2002) a fim de compreender melhor essas ideias. Admita que o espaço geográfico possa ser representado pela linha reta real, pontos ao longo dessa linha representam distâncias em relação ao mercado estrangeiro e são indicados pela variável $x$. A origem dessa linha, ou seja $x=0$, identifica o maior mercado exportador no estrangeiro, enquanto as regiões do país doméstico estão localizadas ao longo do segmento positivo da linha real. Postula-se que o estrangeiro é relativamente mais bem dotado de trabalho qualificado. O modelo admite a existência de dois bens comercializáveis: o bem 1, que pode ser usado tanto para consumo quanto para insumo intermediário, e o bem 2 , que é usado apenas como bem de consumo. Esses dois bens são produzidos com tecnologia de rendimentos constantes de escala utilizando trabalho qualificado $(\mathrm{H})$, trabalho não qualificado (L) e insumo intermediário. O modelo postula imperfeita mobilidade de

${ }^{5}$ Na literatura internacional alguns autores mostram as dificuldades que surgem quando se tenta utilizar o teorema de Stolper-Samuelson para analisar os efeitos da liberalização comercial sobre a remuneração do trabalho menos qualificado em países em desenvolvimento. Ver a respeito em Davis e Mishra (2007). 
fatores de produção dentro do país doméstico. O bem 1 é relativamente intensivo em $\mathrm{H}$, enquanto o bem 2 é relativamente intensivo em L. Assim dadas as hipóteses sobre dotações de fatores, o país doméstico tenderá a exportar o bem 2 e a importar o bem 1 .

Resolvendo o modelo, as variáveis preços dos produtos, preços dos fatores $\mathrm{L}$ e $\mathrm{H}$, quantidade produzida dos bens e custos médios de produção ficam em função, entre outras variáveis, da distância $\mathrm{x}$. No equilíbrio, em qualquer localidade onde um bem seja produzido o custo médio tem que ser igual ao preço do produto, enquanto naquelas localidades onde o bem não é produzido o custo médio deve ser maior que o preço.

Nesse modelo, que inclui a variável distância aos mercados, em equilíbrio os custos de transporte levam à existência de funções preço sobre os espaços. Em particular, quanto mais distante for uma região do mercado estrangeiro, ela receberá preços menores pelo produto de exportação 2, enquanto pagará preços maiores pelo bem 1 que é importado.

A solução do modelo define zonas de especialização segundo os custos de transporte. Regiões com custos de transporte muito elevados podem definir zonas de autarquia $^{6}$, ao passo que regiões com custos de transporte baixos podem se comportar segundo os princípios da teoria Stolper-Samuelson. Os custos de transporte têm implicações em termos de preços dos fatores e níveis de renda real. Assim, o salário relativo do trabalho não qualificado tende a diminuir com a distância aos grandes mercados estrangeiros. Por outro lado, o modelo sugere que a liberalização comercial leva a aumentos de renda real do trabalho não qualificado nas regiões com custos de transporte menores para exportar. Portanto, os efeitos do comércio sobre a distribuição da renda ficam a depender, também, dos custos de transporte no comércio internacional.

\subsection{ASPECTOS METODOLÓGICOS}

A metodologia utilizada neste trabalho tem por objetivo estimar e conhecer melhor os efeitos da liberalização comercial sobre a distribuição da renda em nível de região no Brasil. Utilizando análise apoiada em dados disponíveis e regressões estimadas pretende-se identificar as variáveis que têm contribuído para explicar as mudanças nos diferenciais de salário nas diferentes regiões do Brasil, após a abertura comercial. As estimações utilizam informações sobre os estados brasileiros a fim de melhor avaliar a

${ }^{6}$ Zonas de autarquia distantes do mercado exportador também podem ser definidas caso a participação do insumo intermediário importado no custo médio de produção do bem 2 seja muito elevada. Nesse caso os preços dos bens estão determinados apenas pelas condições locais de oferta e demanda. Aumento no preço internacional do bem 2 não terá efeito sobre a remuneração dos fatores. influência dessas variáveis para explicar as diferenças inter-regionais de salários. Foram estimados dois conjuntos de regressões: um para os estados das regiões de menor desenvolvimento, a ser chamada de região pobre, que compreende os estados das regiões Norte e Nordeste; e outro para os estados das regiões de maior desenvolvimento, a ser chamada de região rica, e que compreende os estados das regiões Sul, Sudeste e Centro Oeste, especificamente ${ }^{7}$.

A fim de realizar uma análise mais aprimorada da relação entre liberalização comercial e distribuição de renda em nível regional, os dados que foram reunidos foram submetidos à análise de regressão. Para realizar essa análise empírica o próximo passo do trabalho foi estabelecer os procedimentos para a construção de algumas variáveis utilizadas nas estimações. Assim, as variáveis utilizadas na análise de regressão foram definidas da seguinte forma:

a) Total de trabalhadores formais ocupados no estado $i$, definido como a soma dos trabalhadores qualificados $\left(H_{\mathrm{i}}\right)$, mais os trabalhadores não qualificados $\left(L_{\mathrm{i}}\right)$;

b) Participação percentual do emprego qualificado em relação ao emprego total no estado $i$, que é igual ao total de trabalhadores formais qualificados do estado $i$ em relação ao total de trabalhadores formais ocupados no estado $i\left(H_{\mathrm{i}} /\right.$ $\left.\left(H_{\mathrm{i}}+L_{\mathrm{i}}\right)\right)$;

c) Salário médio dos trabalhadores qualificados no estado $i(\mathrm{WHi})$, definido como a massa salarial dos trabalhadores qualificados dividida pelo total de trabalhadores qualificados no estado $i$;

d) Salário médio dos trabalhadores não qualificados no estado $i\left(W L_{\mathrm{i}}\right)$ : definido como a relação entre a massa salarial dos trabalhadores não qualificados (expressa em salários mínimos da época) e o total de trabalhadores não qualificados no estado $i$

e) Salário relativo dos trabalhadores não qualificados no estado $i\left(W R_{\mathrm{i}}\right)$ : resultado da divisão do salário médio dos trabalhadores não qualificados $(W L i)$ pelo salário médio dos trabalhadores qualificados no estado $i(W H i)$, isto é, $W R_{\mathrm{i}}=$ $W L_{\mathrm{i}} / W H_{\mathrm{i}}$

f) Coeficiente de abertura simples do estado $i$, definido como o percentual das exportações do estado $i\left(E X P_{\mathrm{i}}\right)$ em relação ao produto interno bruto do estado $i$ $\left(P I B_{\mathrm{i}}\right)$. O valor das exportações do estado $i$ foi obtido do MDIC, Sistema Aliceweb;

g) Índice de Gini (GINI) é o valor do índice de concentração de Gini (obtido da PNAD/IBGE).

A divisão das regiões brasileiras entre ricas e pobres está apoiada no critério do nível de renda per capita de cada região. 
O conjunto de dados que foi reunido combina informações de séries temporais e de séries de corte seccional (cross sections). Desta forma, para modelá-lo, utilizou-se a técnica de dados em painel. A utilização de modelos de dados de painel tem inúmeras vantagens, destacando-se, entre elas, a maior flexibilidade para modelar as diferenças no comportamento entre indivíduos, isto é, o controle da heterogeneidade individual; a menor colinearidade entre as variáveis e o maior grau de liberdade e de eficiência (ver a respeito em Baltagi, 1995; Greene, 2000; Hsiao, 2003).

\section{DADOS UTILIZADOS E RESULTADOS OBTIDOS}

\subsection{DADOS UTILIZADO}

A fim de realizar a análise empírica utilizaram-se dados das seguintes fontes: Relação Anual de Informações Sociais, do Ministério do Trabalho e Emprego (MTE); do Instituto Brasileiro de Geografia e Estatística (IBGE); do Censo de Capitais Estrangeiros, do Banco Central do Brasil e do Sistema Aliceweb, do Ministério do Desenvolvimento, Indústria e Comércio Exterior (MDIC).

Para a análise dos dados e estimação do modelo econométrico foram considerados todos os estados brasileiros, à exceção do estado de Rondônia, para o qual os dados do Censo de Capitais Estrangeiros de 1995 não estavam disponíveis.

Os dados de emprego e rendimentos salariais foram obtidos na Relação Anual de Informações Sociais (RAIS), do Ministério do Trabalho e Emprego (MTE). Foi usada uma variável proxy para qualificação da mão de obra, uma vez que não há como mensurar diretamente o nível de qualificação dos indivíduos. Tendo em vista que os dados utilizados provêm da RAIS, foram usados como proxy para a qualificação os anos de estudo dos trabalhadores. Desta forma, foram classificados como trabalhadores qualificados aqueles trabalhadores que possuíam ensino superior completo ou incompleto e como trabalhadores não qualificados aqueles trabalhadores com níveis de educação inferiores, inclusive analfabetos ${ }^{8}$.

Paralelamente, fez-se um acompanhamento da evolução das variáveis no tempo, destacando-se, entre elas, a evolução do PIB estadual e regional; a estrutura das exportações e das importações; o investimento estrangeiro direto; a relação trabalho qualificado/não qualificado; o salário relativo do trabalhador não qualificado; a desigualdade

${ }_{8}$ Nos anos 2000 e 2005 a RAIS trazia informações dos trabalhadores com mestrado e doutorado. Contudo, no ano de 1995 estas informações não estavam disponíveis. Por este motivo, estes indivíduos foram excluídos da base de dados. da distribuição de renda regional, dados estes a serem descritos a seguir. Finalmente, para construir a proxy dos custos de transporte, buscou-se, no Google Earth (http:// earth.google.com/intl/pt) a informação sobre a distância de cada estado em relação aos centros econômicos dos seus principais parceiros comerciais, ponderando essa distância pela participação de cada parceiro no total das exportações brasileiras dos respectivos anos. Os parceiros comerciais analisados foram os mercados do Nafta, Mercosul, União Europeia e Ásia.

\subsection{CARACTERÍSTICAS DAS REGIÕES BRASILEIRAS E SUA LIGAÇÃO COM A ECONOMIA INTERNACIONAL}

Nesta seção são apresentados alguns indicadores econômicos sobre as regiões brasileiras e sua ligação com a economia internacional. Os indicadores apresentados cobrem o período pós-abertura comercial e fornecem as primeiras evidências das questões que foram levantadas neste trabalho. Na Tabela 1 apresentam-se dados sobre a evolução do produto interno bruto (PIB) per capita em nível regional e a preços do ano de 2000, a tabela mostra também a evolução do PIB per capita de cada região em relação ao PIB per capita do Brasil. Os dados evidenciam as desigualdades inter-regionais de renda na economia brasileira, desigualdades estas já bem documentadas na literatura. A região Nordeste, por exemplo, apresenta renda per capita equivalente a menos da metade da brasileira, ao passo que a renda per capita da região Sudeste do país supera em mais de $30 \%$ a média brasileira. A evolução da renda per capita, ao longo do período considerado de quase 20 anos pós-abertura comercial, pareceria mostrar que a abertura pouco tem contribuído para a convergência das rendas per capita em nível de região no Brasil, principalmente das regiões Norte e Nordeste.

Tabela 1 - Produto Interno Bruto per capita das regiões brasileiras, 1990-2009

\begin{tabular}{lcccccccccc}
\hline \multirow{2}{*}{ Regiões } & \multicolumn{4}{c}{ Anos } & \multicolumn{4}{c}{ PIB per capita regional / PIB per capita nacional (\%) } \\
\cline { 2 - 12 } & $\mathbf{1 9 9 0}$ & $\mathbf{1 9 9 5}$ & $\mathbf{2 0 0 0}$ & $\mathbf{2 0 0 5}$ & $\mathbf{2 0 0 9}$ & $\mathbf{1 9 9 0}$ & $\mathbf{1 9 9 5}$ & $\mathbf{2 0 0 0}$ & $\mathbf{2 0 0 5}$ & $\mathbf{2 0 0 9}$ \\
\hline Norte & 4.500 & 3.920 & 3.870 & 4.560 & 5.130 & 72,00 & 63,74 & 60,20 & 62,00 & 62,80 \\
Nordeste & 2.780 & 2.760 & 3.000 & 3.470 & 3.940 & 44,50 & 44,88 & 46,70 & 47,20 & 48,20 \\
Centro-Oeste & 5.010 & 5.510 & 6.500 & 9.200 & 10.800 & 80,20 & 89,60 & 101,10 & 125,20 & 132,20 \\
Sudeste & 8.610 & 8.460 & 8.710 & 9.750 & 10.700 & 137,80 & 137,56 & 135,50 & 132,70 & 130,90 \\
Sul & 7.560 & 7.380 & 7.650 & 8.320 & 9.330 & 120,96 & 120,00 & 118,90 & 113,20 & 114,20 \\
Brasil & 6.250 & 6.150 & 6.430 & 7.350 & 8.170 & 100,00 & 100,00 & 100,00 & 100,00 & 100,00 \\
\hline
\end{tabular}

Fonte: Elaboração própria com base em dados do IBGE. 
Na Tabela 2 são apresentados indicadores sobre a relação comercial de cada região com o exterior do país. Mostra-se na Tabela 2 a participação de cada região nas exportações totais do Brasil, no período de 1990 a 2009. Os coeficientes evidenciam que as regiões mais desenvolvidas (Sudeste e Sul) têm uma participação nas exportações brasileiras muito maior do que as regiões de menor desenvolvimento (Norte e Nordeste). Mais da metade das exportações brasileiras tem como origem a região Sudeste, enquanto que as regiões Norte e Nordeste continuam relativamente fechadas ao comércio internacional. Cabe, porém, destacar o caso da Região Centro-Oeste, que no período pós-abertura comercial teve um crescimento muito significativo de participação nas exportações brasileiras, passando esta de 1,8\% em 1990 para 9,4\% em 2009. O Centro-Oeste foi a região que teve maior crescimento de participação nas exportações brasileiras; as outras regiões diminuíram a participação ou mantiveram a mesma. Conforme será visto, o crescimento das exportações da região Centro-Oeste aconteceu em produtos primários.

A Tabela 2 mostra, também, nas três últimas colunas, a relação exportações/PIB. Os coeficientes apresentados parecem evidenciar que a economia brasileira continua relativamente fechada ao comércio internacional, pois menos de $10 \%$ do PIB é exportado. Em nível de região cabe destacar novamente o caso da região Centro-Oeste, que teve o maior crescimento na relação exportações/PIB passando de 2,3\% em 1995 para 9,1\% em 2009, aproximando-se do coeficiente brasileiro.

Analisando agora a estrutura do comércio exterior brasileiro percebe-se que o perfil exportador dos estados brasileiros também é bastante diferente, havendo estados, mesmo situados no Centro-Sul do Brasil, fortemente exportadores de produtos agrícolas ou de produtos minerais, enquanto há outros estados com exportações concentradas em produtos industrializados, produtos esses com diferentes graus de conteúdo tecnológico. Conforme o modelo teórico apresentado, essa distinção de produtos exportados é importante para explicar os efeitos da liberalização comercial sobre os rendimentos salariais.

Tabela 2 - Participação das regiões brasileiras nas exportações nacionais e coeficiente exportações/PIB

\begin{tabular}{lccccrrrr}
\hline \multirow{2}{*}{ Regiões } & \multicolumn{3}{c}{ Exportações regionais/exportações nacionais (\%) } & \multicolumn{3}{c}{ Exportações/PIB (\%) } \\
\cline { 2 - 9 } & $\mathbf{1 9 9 0}$ & $\mathbf{1 9 9 5}$ & $\mathbf{2 0 0 0}$ & $\mathbf{2 0 0 5}$ & $\mathbf{2 0 0 9}$ & $\mathbf{1 9 9 5}$ & $\mathbf{2 0 0 0}$ & \multicolumn{2}{c}{$\mathbf{2 0 0 9}$} \\
\hline Norte & 5,79 & 5,32 & 6,24 & 6,36 & 6,71 & 7,44 & 12,00 & 12,37 \\
Nordeste & 9,78 & 9,28 & 7,57 & 9,05 & 7,71 & 4,70 & 5,11 & 5,30 \\
Centro-Oeste & 1,81 & 2,16 & 3,44 & 6,15 & 9,37 & 2,34 & 4,38 & 9,07 \\
Sudeste & 60,78 & 58,29 & 58,53 & 56,08 & 54,38 & 6,43 & 8,95 & 9,13 \\
Sul & 21,83 & 24,95 & 24,22 & 22,36 & 21,83 & 9,03 & 12,18 & 12,26 \\
Brasil & 100,00 & 100,00 & 100,0 & 100,00 & 100,00 & 6,48 & 8,54 & 9,43 \\
\hline
\end{tabular}

Fonte: Elaboração própria com base em dados da SECEXIMDIC e do IBGE.
Na Tabela 3, a seguir, é apresentada a estrutura das exportações das regiões brasileiras segundo grupos de produtos ${ }^{9}$, para o período 1990-2012. Observa-se que os grupos de produtos de Alimentos e Bebidas, e de Minerais, que sabidamente têm forte conteúdo de recursos naturais e baixo valor agregado, são os grupos que durante o período apresentam a maior representatividade dentro das exportações das regiões brasileiras. No ano de 2012 a participação desses dois grupos de produtos nas exportações totais das Regiões Centro-Oeste, Norte, Sul, Sudeste e Nordeste corresponderam a $87,1 \%, 76,4 \%, 52,1 \%, 52,1 \%$ e $44,7 \%$, respectivamente. A participação dos produtos primários aumentou durante o período, principalmente nas regiões Norte, Sul e Sudeste. Observa-se que nos últimos anos esses grupos de produtos primários intensificaram a participação na pauta de exportações, contribuindo para a primarização das exportações brasileiras e a correspondente queda de participação dos produtos manufaturados.

Com relação às exportações dos grupos de produtos industrializados observa-se que as mesmas estão concentradas na região Sudeste e em menor grau nas regiões Sul e Nordeste. A Tabela 3 mostra, por exemplo, que uma participação significativa das exportações da região Sudeste consiste de produtos dos grupos de Máquinas e Equipamentos e Material de transporte, produtos estes tradicionalmente intensivos em capital, e que têm alto valor agregado.

A Tabela 4 mostra a evolução do perfil das importações das regiões brasileiras segundo os diferentes grupos de produtos para o período 1990-2012. Diferente das exportações, as importações das regiões brasileiras estão concentradas em produtos manufaturados. Observa-se uma redução significativa na participação relativa das importações de produtos primários, principalmente do grupo de Alimentos e Bebidas. Por outro lado, as importações de produtos manufaturados tiveram um crescimento significativo na participação relativa após a abertura comercial. Essa mudança no perfil importador certamente teve impactos sobre o mercado de trabalho nas diferentes regiões brasileiras. Cabe destacar o grupo de Máquinas e Equipamentos como sendo o principal item industrializado importado pelas regiões Sudeste, Sul, Nordeste e Norte. Conforme ressaltado, esses produtos são intensivos em capital e têm elevado valor agregado. No caso da região Centro-Oeste o principal grupo manufaturado importado o constitui o de Produtos Químicos.

Na Tabela 5 é apresentado outro indicador de globalização para o Brasil, referente ao investimento estrangeiro direto (IED) em nível de região brasileira, dados relativos

9 O critério de agrupação dos produtos segue de perto aquele sugerido por Thorstensen et al. (1994), critério este muito utilizado em diversos trabalhos sobre comércio exterior. 

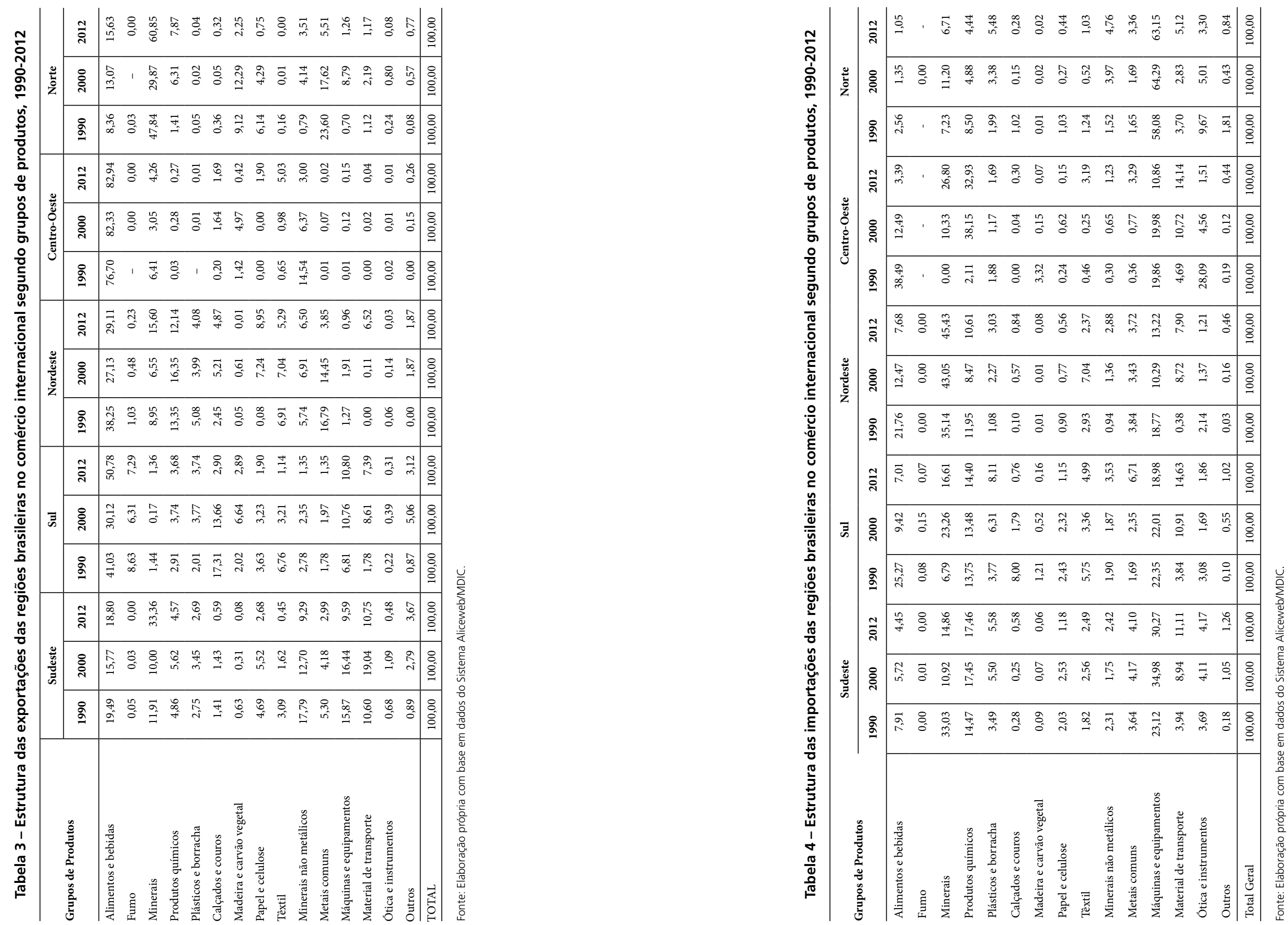
ao período de 1995 a $2005^{10}$. Observa-se na Tabela 5 uma alta concentração do IED nas regiões mais ricas, principalmente na região Sudeste. Com efeito, no período analisado, mais de $85 \%$ do investimento estrangeiro direto foram direcionados para a região Sudeste. Por outro lado, regiões de menor desenvolvimento relativo, tais como o Norte e o Nordeste, tiveram pouca participação no IED. No caso da região Nordeste, a participação do IED situa-se por volta de 3\%, enquanto que na região Norte a participação no último ano pesquisado é de pouco mais de $1 \%$, e com tendência de queda. Dessa forma, sob a ótica do IED, as regiões brasileiras também parecem estar diferentemente integradas à economia internacional.

\section{Tabela 5 - Estoque de IED no Brasil e regiões} (ano-base 1995)

\begin{tabular}{lrrrrrr}
\hline Regiões & \multicolumn{3}{c}{ Em US\$ milhões } & \multicolumn{3}{c}{ Em percentual } \\
& $\mathbf{1 9 9 5}$ & $\mathbf{2 0 0 0}$ & $\mathbf{2 0 0 5}$ & $\mathbf{1 9 9 5}$ & $\mathbf{2 0 0 0}$ & \multicolumn{1}{c}{$\mathbf{0 0 5}$} \\
\hline Norte & 841 & 1.571 & 2.114 & 2,02 & 1,53 & 1,30 \\
Nordeste & 1.618 & 3.187 & 5.511 & 3,89 & 3,10 & 3,39 \\
Centro-Oeste & 218 & 1.304 & 2.473 & 0,52 & 1,27 & 1,52 \\
Sudeste & 36.683 & 89.322 & 139.710 & 88,09 & 86,79 & 85,86 \\
Sul & 2.284 & 7.529 & 12.920 & 5,48 & 7,32 & 7,94 \\
Brasil & 41.644 & 102.912 & 162.727 & 100,00 & 100,00 & 100,00 \\
\hline
\end{tabular}

Fonte: Elaboração própria com base em dados do Censo de Capitais Estrangeiros do Banco Central do Brasil, vários anos.

A fim de ter um conhecimento inicial sobre a relação entre abertura e distribuição de renda em nível regional, nas Tabelas 6, 7 e 8 são apresentados indicadores de salário médio da mão de obra qualificada (WH), e salário médio da mão de obra não qualificada (WL) para o período de 1990 a 2010. A Tabela 6 apresenta os salários médios regionais do pessoal ocupado qualificado como proporção do salário médio nacional, também do pessoal ocupado qualificado. A Tabela 7 apresenta a mesma informação, porém, referente à mão de obra não qualificada.

Os dados das Tabelas 6 e 7 mostram que os salários médios, tanto do trabalho qualificado quanto do trabalho não qualificado das regiões Sudeste e Centro-Oeste, situam-se acima da média nacional. É possível, porém, que os dados para o Centro-Oeste estejam influenciados pelos dados para o Distrito Federal.

${ }^{10}$ Os dados apresentados têm como fonte o Censo de Capitais Estrangeiros no País, que é realizado a cada cinco anos pelo Banco Central do Brasil, tendo como ano-base 1995. O objetivo do censo é mensurar o estoque de IED no país na posição de 31 de dezembro de cada ano pesquisado.
Tabela 6 - Remuneração do pessoal qualificado: salários médios regionais/salário médio nacional (em \%)

\begin{tabular}{lrrrrrr}
\hline \multirow{2}{*}{ Regióes } & \multicolumn{7}{c}{ Anos } \\
\cline { 2 - 7 } & $\mathbf{1 9 9 0}$ & $\mathbf{1 9 9 4}$ & $\mathbf{2 0 0 1}$ & $\mathbf{2 0 0 4}$ & \multicolumn{1}{c}{$\mathbf{2 0 0 7}$} & \multicolumn{1}{c}{$\mathbf{2 0 1 0}$} \\
\hline Norte & 98,28 & 86,55 & 96,22 & 96,55 & 93,56 & 90,86 \\
Nordeste & 77,18 & 79,25 & 71,07 & 70,88 & 75,58 & 78,02 \\
Centro Oeste & 135,98 & 123,60 & 122,13 & 129,44 & 135,14 & 132,68 \\
Sudeste & 102,71 & 108,53 & 108,54 & 106,57 & 105,89 & 106,14 \\
Sul & 85,78 & 80,40 & 87,95 & 92,19 & 88,57 & 87,15 \\
Brasil & 100,00 & 100,00 & 100,00 & 100,00 & 100,00 & 100,00 \\
\hline
\end{tabular}

Fonte: Elaboração própria com base em dados da RAIS/MTE.

Conforme foi visto no modelo teórico apresentado na seção 2 deste trabalho, os efeitos do comércio sobre a distribuição de renda em nível regional podem ser mais bem compreendidos com base no comportamento dos salários relativos do trabalho não qualificado em relação ao trabalho qualificado (WL/WH). Com efeito, a Tabela 8 apresenta a evolução dos salários relativos (WL/WH) em nível regional durante o período analisado, cuja evolução corrobora alguns dos resultados do modelo.

Tabela 7 - Remuneração do pessoal não qualificado: salários médios regionais/salário médio nacional (em \%)

\begin{tabular}{lrrrrrr}
\hline \multirow{2}{*}{ Regióes } & \multicolumn{7}{c}{ Anos } \\
\cline { 2 - 7 } & $\mathbf{1 9 9 0}$ & $\mathbf{1 9 9 4}$ & $\mathbf{2 0 0 1}$ & $\mathbf{2 0 0 4}$ & $\mathbf{2 0 0 7}$ & $\mathbf{2 0 1 0}$ \\
\hline Norte & 98,66 & 85,27 & 91,57 & 93,59 & 96,77 & 98,29 \\
Nordeste & 76,96 & 85,71 & 71,94 & 74,22 & 77,86 & 82,69 \\
Centro-Oeste & 125,50 & 104,69 & 106,60 & 105,51 & 109,99 & 109,89 \\
Sudeste & 107,38 & 109,15 & 111,06 & 109,54 & 107,70 & 106,25 \\
Sul & 92,84 & 88,62 & 93,15 & 97,02 & 96,00 & 96,12 \\
Brasil & 100,00 & 100,00 & 100,00 & 100,00 & 100,00 & 100,00 \\
\hline
\end{tabular}

Fonte: Elaboração própria com base em dados da RAIS/MTE.

Os salários relativos $(\mathrm{WL} / \mathrm{WH})$ das regiões mais desenvolvidas, Sudeste e Sul, apresentam-se maiores do que os salários médios relativos para o Brasil para todos os anos considerados. Esse comportamento dos salários relativos parece indicar que de alguma forma o efeito Stolper-Samuelson está presente nessas regiões, pois são as regiões mais abertas à economia internacional, conforme foi visto acima. Também merece ser destacado o fato de a região Centro-Oeste apresentar salários relativos (WL/ WH) menores do que os salários relativos para o Brasil e regiões Sudeste e Sul, para todos os anos considerados. 
Tabela 8 - Salário médio regional do pessoal não-qualificado/salário médio regional do pessoal qualificado (em \%), 1990-2010

\begin{tabular}{lcccccc}
\hline \multirow{2}{*}{ Regiões } & \multicolumn{7}{c}{ Anos } \\
\cline { 2 - 7 } & $\mathbf{1 9 9 0}$ & $\mathbf{1 9 9 4}$ & $\mathbf{2 0 0 1}$ & $\mathbf{2 0 0 4}$ & $\mathbf{2 0 0 7}$ & $\mathbf{2 0 1 0}$ \\
\hline Norte & 29,68 & 33,92 & 26,74 & 28,78 & 32,04 & 33,46 \\
Nordeste & 29,48 & 37,24 & 28,44 & 31,08 & 31,92 & 32,78 \\
Centro-Oeste & 27,28 & 29,17 & 24,52 & 24,20 & 25,21 & 25,61 \\
Sudeste & 30,91 & 34,64 & 28,76 & 30,52 & 31,51 & 30,97 \\
Sul & 32,00 & 37,96 & 29,77 & 31,25 & 33,59 & 34,12 \\
Brasil & 29,56 & 34,44 & 28,10 & 29,69 & 30,99 & 30,93 \\
\hline
\end{tabular}

Fonte: Elaboração própria com base em dados da RAIS/MTE.

Conforme ressaltado anteriormente, a região Centro-Oeste foi a que mais cresceu em participação nas exportações brasileiras. Por outro lado, o comportamento dos salários relativos para as regiões Nordeste e Norte não parece conclusivo, explicado em parte pelo fato de serem regiões que se mantiveram relativamente fechadas à economia internacional, principalmente no caso do Nordeste. Nesta última região apenas pouco mais de 5\% do PIB é exportado (ver a Tabela 2).

Na Tabela 9 apresentam-se indicadores sobre a desigualdade na distribuição de renda nas diversas regiões do país. Os indicadores apresentados são os índices de Gini para alguns anos do período 1999 a 2009. O índice de Gini situa-se no intervalo entre zero e a unidade, índice de Gini igual à unidade significa alta concentração na distribuição da renda, ao passo que índice de Gini com valor zero significa distribuição igualitária.

Os índices da Tabela 9 mostram que a desigualdade na distribuição de renda é menor nas regiões Sudeste, Sul e Norte do que nas regiões Nordeste e Centro-Oeste. A região Centro-Oeste é a região que apresenta a maior desigualdade na distribuição da renda no Brasil.

Tabela 9 - Desigualdade na distribuição da renda segundo as regiões brasileiras, 1999 - 2009, Índice de Gini

\begin{tabular}{lcccc}
\hline \multirow{2}{*}{ Regiões } & \multicolumn{3}{c}{ Anos } \\
\cline { 2 - 5 } & $\mathbf{1 9 9 9}$ & $\mathbf{2 0 0 5}$ & $\mathbf{2 0 0 8}$ & $\mathbf{2 0 0 9}$ \\
\hline Norte & 0,54 & 0,53 & 0,49 & 0,52 \\
Nordeste & 0,58 & 0,57 & 0,54 & 0,56 \\
Centro-Oeste & 0,57 & 0,58 & 0,57 & 0,56 \\
Sudeste & 0,53 & 0,54 & 0,50 & 0,51 \\
Sul & 0,54 & 0,52 & 0,49 & 0,49 \\
Brasil & 0,56 & 0,57 & 0,51 & 0,54 \\
\hline
\end{tabular}

Fonte: Elaborada com base em dados da PNAD/BGE.

\subsection{RESULTADOS OBTIDOS NA ANÁLISE ECONOMÉTRICA}

Foi utilizado o modelo de dados de painel, estimado inicialmente para efeitos fixos e aleatórios. Os resultados dos testes indicaram ser necessária uma nova estimação de painel FGLS (Mínimos Quadrados Generalizados Factíveis), resultados que serão mostrados nesta seção.

Com base no modelo teórico apresentado na seção 2 deste trabalho, utilizou-se o seguinte modelo a ser estimado:

$$
W R_{i t}=\beta_{0}+\beta_{1}(H /(H+L))_{i t}+\beta_{2} G I N I_{i t}+\beta_{3} E X P_{i t}+\beta_{4} D I S T_{i t}+e_{i t}
$$

$\mathrm{Na}$ expressão acima:

$i$ é o índice para o estado com $i=1, \ldots, N$;

$t$ é o índice das unidades de tempo, $t=1, \ldots, T$;

$W R_{i t}$ é o salário relativo dos trabalhadores não qualificados no estado $i$ no período $t$;

$(H /(H+L))_{i t}$ é a participação percentual do emprego qualificado em relação ao emprego total no estado $i$ no período $t$;

GINI é o índice de Gini do estado $i$ no período $t$;

EXP $P_{i t}$ é o percentual correspondente ao valor das exportações do estado $i$ dividido pelo produto interno bruto do estado $i$ no período $t$;

$D I S T_{i t}$ representa a distância do estado $i$ em relação aos principais parceiros comerciais nos mercados estrangeiros do Nafta, Mercosul, União Europeia e Ásia no período $t^{11}$; e

$\varepsilon_{i t}$ é o termo erro no estado $i$ no período $t$.

A seguir será indicado o sinal esperado para cada uma das variáveis levando em conta o modelo teórico apresentado na seção 2 deste trabalho. Estados com maior PIB per capita (estados ricos) exercem atração sobre a mão de obra qualificada, de sorte que a proporção de trabalhadores qualificados disponíveis tende a ser maior do que nas economias com menor PIB per capita (estados pobres). Assim, espera-se um prêmio menor para os trabalhadores qualificados nessas economias e, portanto, um sinal positivo para o coeficiente $\beta_{1}$.

Por outro lado, o sinal esperado para o coeficiente da variável índice de GINI, $\beta_{2}$ é negativo, indicando que, quanto maior a desigualdade na distribuição de renda, menor será o salário relativo do trabalho não qualificado.

${ }^{11}$ Nas regressões que serão apresentadas a seguir a variável distância foi ponderada pelo inverso da corrente de comércio. 
Com relação ao coeficiente da variável participação das exportações no PIB, se as previsões do modelo apresentado na seção 2 são válidas, $\beta_{3}$ será negativo para as regiões pobres e positivo para as regiões ricas. Este sinal esperado é crucial para testar a evidência empírica do modelo acima apresentado.

Finalmente, em relação à variável distância, proxy para os custos de transporte, o modelo apresentado prevê que dada a hipótese sobre abundância relativa de fatores, 0 salário relativo do trabalho não qualificado tende a diminuir com a distância aos grandes mercados internacionais. Quanto maior a distância do estado $i$ para os principais mercados de exportação, mais os salários estarão determinados principalmente pelas condições locais e menos pelas condições internacionais. Assim, o sinal esperado para esta variável é negativo.

O modelo econométrico foi estimado através do programa Data Analysis and Statistical Software - STATA 10.0, com variável dependente salário relativo do trabalhador não qualificado $\left(W R_{i t}\right)$. Foram estimados painéis pooled OLS (mínimos quadrados ordinários), com efeitos fixos e efeitos aleatórios e realizados os devidos testes para detectar a presença (ou não) de heterocedasticidade e autocorrelação.

Detectou-se a presença de heterocedasticidade nos modelos estimados. Assim, como recomenda Wooldridge (2001), na presença de autocorrelação e/ou heterocedasticidade, o correto é estimar os modelos através do método de Mínimos Quadrados Generalizados Factíveis (FGLS). Por este motivo, nas Tabelas 10 e 11, a seguir, serão reportados somente os resultados obtidos nos modelos estimados a partir do método de FGLS com correção de heterocedasticidade.

Com a finalidade de verificar se os resultados encontrados para a região rica estão influenciados pelo Distrito Federal, foram estimados dois grupos de regressões, um primeiro grupo excluindo as observações para o Distrito Federal e um segundo grupo de regressões incluindo as observações para o Distrito Federal. Os resultados obtidos em ambos os casos são semelhantes. Desta forma, os resultados para a região rica serão os obtidos com a exclusão do Distrito Federal.

A Tabela 10 mostra as regressões obtidas para a região pobre, enquanto a Tabela 11 mostra os resultados obtidos para a região rica, segundo critérios de região definidos anteriormente.

Primeiramente, destaca-se que todas as variáveis, exceto a distância para alguns destinos, foram significativas, e com o sinal esperado correto em todas as regressões, e que os resultados do teste de Wald demonstram o bom ajustamento do modelo.

Verifica-se que tanto para a região pobre quanto para a região rica o sinal do coeficiente da variável emprego relativo $\left(H_{\mathrm{i}} /\left(H_{\mathrm{i}}+L_{\mathrm{i}}\right)\right)$ foi positivo, indicando que para o período considerado um aumento no emprego do trabalho qualificado em relação ao emprego total contribuiu para aumentar o salário relativo do trabalho não qualificado, o que é coerente com as previsões teóricas. À medida que a participação do trabalho qualificado no emprego total cresce, a desigualdade salarial se reduz em ambas as regiões. Isto sinaliza a importância de políticas públicas que promovam a qualificação da mão de obra para a diminuição da desigualdade no Brasil.

Tabela 10 - Região pobre, resultados da estimação do modelo de efeitos aleatórios - Variável dependente: salário relativo do trabalhador não qualificado (WR

\begin{tabular}{lcccc}
\hline \multirow{2}{*}{ Variáveis independentes } & \multicolumn{4}{c}{ Coeficientes e nível de significância } \\
\cline { 2 - 5 } & $(\mathbf{1})$ & $\mathbf{( 2 )}$ & $\mathbf{( 3 )}$ & $(\mathbf{4})$ \\
\hline Intercepto & 0,4637752 & 0,4142161 & 0,6110731 & 0,497812 \\
& $(0,000)$ & $(0,000)$ & $(0,000)$ & $(0,000)$ \\
Emprego Qualificado/Emprego Total & 0,007543 & 0,0069483 & 0,0069344 & 0,0069487 \\
& $(0,000)$ & $(0,000)$ & $(0,000)$ & $(0,000)$ \\
Coeficiente de Gini & $-0,3340856$ & $-0,4294466$ & $-0,4311964$ & $-0,4326148$ \\
& $(0,000)$ & $(0,000)$ & $(0,000)$ & $(0,000)$ \\
Percentual das exportações do estado $i$ & $-0,0000732$ & $-0,0000635$ & $-0,0000626$ & $-0,0000608$ \\
em relação ao PIB do estado $i$ & $(0,001)$ & $(0,005)$ & $(0,006)$ & $(0,008)$ \\
Distância & $-0,0109499$ & 0,0124241 & $-0,0096008$ & $-0,0046315$ \\
& $(0,019)$ & $(0,063)$ & $(0,101)$ & $(0,245)$ \\
Teste de Wald $\chi^{2}$ (4 g. l.) & 161,47 & 157,35 & 155,77 & 153,04 \\
Número total de observações & 144 & 144 & 144 & 144 \\
\hline
\end{tabular}

Nota: Nas regressōes (1), (2) e (3) a variável distância refere-se à distância do estado $i$ em relação aos principais parceiros dos blocos do Nafta, Mercosul e União Europeia, respectivamente; na regressão (4) a distância é em relação à China. Os valores entre parenteses sao os pralues.

Tabela 11 - Região rica, resultados da estimação do modelo de efeitos aleatórios - Variável dependente: salário relativo do trabalhador não qualificado (WR)

\begin{tabular}{lcccc}
\hline \multirow{2}{*}{ Variáveis independentes } & \multicolumn{4}{c}{ Coeficientes e nível de significância } \\
\cline { 2 - 5 } & $\mathbf{( 1 )}$ & $\mathbf{( 2 )}$ & $\mathbf{( 3 )}$ & $\mathbf{( 4 )}$ \\
\hline Intercepto & 0,4715201 & 0,4582672 & 0,2675191 & 0,159146 \\
& $(0,000)$ & $(0,000)$ & $(0,012)$ & $(0,327)$ \\
Emprego Qualificado/Emprego Total & 0,0020048 & 0,0020716 & 0,0021533 & 0,0020895 \\
& $(0,011)$ & $(0,007)$ & $(0.005)$ & $(0,007)$ \\
Coeficiente de Gini & $-0,374444$ & $-0,3121993$ & $-0,3078994$ & $-0,3104632$ \\
& $(0,000)$ & $(0,000)$ & $(0,000)$ & $(0,000)$ \\
Percentual das exportações do estado $i$ & 0,0000902 & 0,0001068 & 0,0001021 & 0,0001059 \\
em relação ao PIB do estado $i$ & $(0,055)$ & $(0,020)$ & $(0,024)$ & $(0,020)$ \\
Distância & $-0,0005935$ & $-0,0149238$ & 0,0165562 & 0,0154937 \\
& $(0,937)$ & $(0,056)$ & $(0,038)$ & $(0,047)$ \\
Teste de Wald $\chi^{2}$ (4 g. l.) & 45,66 & 52,77 & 53,47 & 53,07 \\
& $(0,000)$ & $(0,000)$ & $(0,000)$ & $(0,000)$ \\
Número total de observações & 90 & 90 & 90 & 90 \\
\hline
\end{tabular}

Nota: Nas regressōes (1), (2) e (3) a variável distância refere-se à distância do estado $i$ em relação aos principais parceiros dos blocos do Nafta, Mercosul e União Europeia, respectivamente; na regressão (4) a distância é em relaçăo à China. Os valores entre parenteses sáo os p-value El 
Por outro lado o sinal obtido para o coeficiente da variável coeficiente de Gini foi negativo e significativo, conforme esperado. De fato, há uma estreita relação entre essas duas variáveis, uma vez que os salários fazem parte da renda dos indivíduos. Destaca-se que foram estimados outros modelos nos quais a variável Gini foi retirada da equação e que os sinais dos coeficientes permaneceram inalterados, sinalizando a robustez do modelo.

O ponto fundamental do modelo proposto na seção 2 deste trabalho é que a partir da abertura comercial a região pobre experimentará um aumento na desigualdade de renda, enquanto a região rica apresentará uma redução na desigualdade salarial entre trabalhadores qualificados e não qualificados. Os resultados obtidos nas regressões mostraram-se consistentes com essa previsão. $\mathrm{O}$ coeficiente estimado para a variável participação das exportações do estado $i$ no produto interno bruto do estado $i$ foi negativo e significativo para a região pobre (estados das regiões Norte e Nordeste), e positivo e significativo para a região rica (estados das regiões Sudeste, Sul e Centro-Oeste).

Finalmente, o sinal obtido para o coeficiente da variável distância, proxy para os custos de transporte, foi negativo e significativo para alguns destinos, porém, para outros países, mais distantes, o sinal obtido foi positivo no caso da região rica. Assim, para a região rica o sinal obtido para distância foi negativo e significativo para os destinos mais próximos, Mercosul e Nafta, enquanto que para os destinos comerciais mais distantes, como é o caso da União Europeia e da China, o sinal obtido foi positivo. Esse resultado parece sinalizar que quanto maior a distância do mercado exportador, os preços dos fatores estão determinados pelas condições locais e menos influenciados pelas condições internacionais. Por outro lado, para a região pobre, obteve-se coeficiente estimado negativo para os destinos comerciais: Nafta, União Europeia e a China, porém, positivo e significativo para o Mercosul.

\section{CONCLUSÕES}

A relação entre abertura, comércio e distribuição de renda no Brasil tem sido objeto de diversos estudos, porém, nem sempre com resultados conciliatórios. Este trabalho teve por objetivo estudar os efeitos da abertura comercial e da globalização sobre a distribuição de renda no Brasil, levando em conta a dimensão espacial, a qual geralmente é negligenciada nos trabalhos realizados.

Os resultados encontrados parecem mostrar que a liberalização comercial levou a movimentos opostos nos salários relativos em cada uma das regiões consideradas. Os dados reunidos mostram que no caso das regiões mais desenvolvidas o comportamento dos salários relativos parece seguir as previsões da teoria de Stolper-Samuelson, ao passo que, nas regiões em desenvolvimento (regiões Norte e Nordeste), os salários relativos para o trabalho não qualificado apresentam-se menores, em consonância com o modelo teórico apresentado. Em outras palavras, a abertura comercial parece ter contribuído para a melhoria na distribuição de renda das regiões mais ricas, mas parece ter contribuído para a piora na distribuição de renda das regiões de menor desenvolvimento relativo.

A dimensão espacial pode ter contribuído para esse aumento na desigualdade nos estados de menor desenvolvimento relativo. Desta forma, os benefícios da globalização parecem ter sido distribuídos de forma desigual.

Os resultados obtidos evidenciam a importância das políticas públicas que promovam a qualificação da mão de obra com o objetivo de reduzir a desigualdade salarial nas regiões brasileiras. Paralelamente, são desejáveis políticas que fortaleçam as interligações entre os estados mais isolados do comércio internacional e aqueles estados mais integrados à economia internacional, a fim de distribuir melhor os ganhos do comércio do ponto de vista geográfico.

Trabalhos futuros podem ser direcionados no sentido de incorporar ao modelo econométrico o conteúdo das exportações, bem como realizar pesquisas em nível de firmas, cruzando dados de produção, emprego, salários e comércio exterior.

\section{REFERÊNCIAS}

ARBACHE, J. S.; CORSEUIL, C. H. Liberalização comercial e estruturas de emprego e salário Revista Brasileira de Economia, v. 58, n. 4, 2004.

ARBACHE, J. S.; CORSEUIL, C. H. "Comércio internacional, competitividade e mercado de trabalho: algumas evidências para o Brasil”. In: CORSEUIL, C. H.; KUME, H. A abertura comercial brasileira nos anos 1990: impactos sobre emprego e salário. Rio de Janeiro: IPEA, 2003, p. 115-167.

BALTAGI, B. H. Econometric analysis of panel data. 3 ed. Chichester: John Wiley \& Sons, 1995.

BARROS, R. P.; CORSEUIL, C. H.; CURY, S.; LEITE, P. G. Abertura econômica e distribuição de renda no Brasil. In: Workshop Liberalização Comercial IPEA/UnB/MTE, 2001. Brasília, abr. 2001.

CAMPOS, M. F. S. S.; HIDALGO, A. B.; DA MATA, D. F. G.; Abertura, comércio intra-indústria e desigualdade de rendimentos: uma análise para a indústria de transformação brasileira. Revista Nova Economia, v. 17, n. 2, p. 275-306, 2007a.

CAMPOS, M. F. S. S.: HIDALGO, A. B. DA MATA, D. F. G. Comércio intra-indústria e desigualdade de rendimentos nas firmas da indústria brasileira. EconomiA, Campinas, v. 8, p. $97-122,2007 b$ 
CHIQUIAR, D. Globalization regional wage differentials and the Stolper-Samuelson theorem: evidence from México. Journal of International Economics, v. 74, p. 70-93, 2008.

DAVIS, D. R.; MISHRA, P. "Stolper-Samuelson Is dead: and other crimes of both theory and data”. In: HARRISON, A. (Ed.) Globalization and poverty. Chicago: University of Chicago Press, 2007, p. 87-107.

DE NEGRI, J. A. A influência das economias de escala e dos rendimentos crescentes de escala no desempenho exportador das firmas industriais no Brasil. In: Encontro Nacional de Economia, 31, Porto Seguro/BA, dez. 2003.

DE NEGRI, J. A. ; FREITAS, F. ; COSTA, G. ; SILVA, A. ; ALVES, P. ."Tipologia das firmas integrantes da indústria brasileira”. In: DE NEGRI, J. A.; SALERNO, M. S. (Orgs.) Inovações, padrões tecnológicos e desempenho das firmas industriais brasileiras. Brasília: IPEA, 2005, p. 689-713.

FERREIRA, A. H. B.; MACHADO, A. F. Trade, wage and employment. In: Workshop Liberalização Comercial IPEA/UnB/TEM, Brasília, abr. 2001.

GREENE, W. H. Econometric analysis. 4 ed. New Jersey: Prentice Hall, 2000.

HIDALGO, A. B.; DA MATA, D. F, G. Produtividade e desempenho exportador das firmas na indústria de transformação brasileira. Revista Estudos Econômicos, v. 39, p. 709-735, 2009.

HIDALGO, A. B., O processo de abertura comercial brasileira e o crescimento da produtividade. Revista Economia Aplicada, v. 6, n. 1, p. 79-95, 2002.

HSIAO, C. Analysis of panel data. 2 ed. Cambridge: Cambridge University Press, 2003.

LERNER, A. The diagrammatical representation of cost conditions in international trade. Economica, v.12, p. 346-356, 1932.

MACHADO, A. F.; MOREIRA, M. M. Os impactos da abertura comercial sobre a remuneração relativa do trabalho no Brasil. Revista Economia Aplicada, v. 5, n. 3, p. 491-517, 2001.

PEDROSO, A. C. S.; FERREIRA, P. C. Abertura comercial e disparidade de renda entre países: uma análise empírica. IPEA: Rio de Janeiro, 2000.

SACCONATO, A. L.; MENEZES-FILHO, N. A. O que explica a diferença de rendimentos entre trabalhadores americanos e brasileiros? Uma análise com microdados. Pesquisa e Planejamento Econômico, v. 35, n. 3, p. 333-354, 2005.

SAMUELSON, P. A. The transfer problem and transport costs: analysis of effects of trade impediments. Economic Journal, v. 64, n. 254, p. 264-289, 1954.

THORSTENSEN,V. ; NAKANO, Y. ; LIMA, C.; SATO, C. O Brasil frente a um mundo dividido em blocos. São Paulo: Instituto Sul-Norte, 1994.

VENABLES, A.; LIMÃO, N. Geographical disadvantage: A Heckscher-Ohlin-Von Thunen model of international specialization. Journal of International Economics, v. 58, n. 2, p. 239-263, 2002 .

WOOLDRIDGE, J. M. Econometric analysis of cross section and data panel. Cambridge, MA: MIT Press, 2001. 